\title{
Predictors of transient congenital hypothyroidism in children with eutopic thyroid gland
}

\author{
Il Soon Park, MD, \\ Jong Seo Yoon, MD, \\ Cheol Hwan So, MD, \\ Hae Sang Lee, MD, PhD, \\ Jin Soon Hwang, MD, PhD
}

Department of Pediatrics, Ajou University Hospital, Ajou University School of Medicine, Suwon, Korea
Received: 11 October, 2016

Revised: 10 November, 2016

Accepted: 20 December, 2016

Address for correspondence:

Hae Sang Lee, MD, PhD

Department of Pediatrics, Ajou

University School of Medicine, 206

World cup-ro, Yeongtong-gu, Suwon 16499, Korea

Tel: +82-31-219-5166

Fax: +82-31-219-5169

E-mail:seaon98@naver.com

https://orcid.org/0000-0002-96844042
Purpose: Congenital hypothyroidism $(\mathrm{CH})$ is the most common cause of preventable mental retardation. Recently, the detection of $\mathrm{CH}$ cases with eutopic thyroid gland has increased due to neonatal screening programs. In this study, we aimed to identify and evaluate predictive factors that could distinguish between permanent and transient $\mathrm{CH}$ in patients with eutopic thyroid gland.

Methods: We retrospectively reviewed 100 children diagnosed with $\mathrm{CH}$ and with eutopic thyroid gland. All subjects were treated with levothyroxine and underwent re-evaluation after 3 years of age.

Results: Of the $100 \mathrm{CH}$ patients, 35 (35.0\%) were diagnosed with permanent $\mathrm{CH}$ $(\mathrm{PCH})$ and 65 (65.0\%) were diagnosed with transient $\mathrm{CH}(\mathrm{TCH})$. The initial thyroid stimulating hormone levels were significantly lower in the TCH subjects than in $\mathrm{PCH}$ subjects. In addition, the mean doses of levothyroxine $(\mu \mathrm{g} / \mathrm{kg} /$ day) at the $1 \mathrm{st}, 2 \mathrm{nd}$, and 3rd year of treatment were significantly lower in subjects with TCH than in PCH subjects with eutopic thyroid gland. Based on the receiver operating characteristic (ROC) curve, the optimal cutoff dose of levothyroxine at 3 years of $2.76 \mu \mathrm{g} / \mathrm{kg} / \mathrm{day}$ could predict $\mathrm{TCH}$, and was associated with $87.3 \%$ sensitivity and $67.6 \%$ specificity, with an area under the ROC curve of 0.769 .

Conclusion: The levothyroxine dose requirement during treatment period has a predictive role in differentiating $\mathrm{TCH}$ from $\mathrm{PCH}$ in $\mathrm{CH}$ patients with eutopic thyroid gland.

Keywords: Congenital hypothyroidism, Thyroid gland, Therapeutics

\section{Introduction}

Congenital hypothyroidism $(\mathrm{CH})$ is the most common endocrine diseases of childhood, leading to permanent mental retardation if not treated in the early infancy ${ }^{1)}$. In industrialized countries, neonatal screening tests has enabled early diagnosis of $\mathrm{CH}$ in neonates, and consequently, severe mental retardation due to $\mathrm{CH}$ is very rare ${ }^{2,3)}$.

Due to the neonatal screening programs, the incidence of $\mathrm{CH}$ has increased in many countries around the world ${ }^{4,5)}$. Further, improved thyroid stimulating hormone (TSH) assay sensitivity and lower cutoffs in the screening program have resulted in an increase in $\mathrm{CH}$ diagnoses. Owing to these changes in the newborn screening tests, the detection of mild forms of $\mathrm{CH}$ associated with eutopic and normal-shaped thyroid glands have increased progressively $^{6}$. Current guidelines recommend that all children with $\mathrm{CH}$ need a re-evaluation of their thyroid function tests after 3 years of age; a condition where a levothyroxine treatment is no longer required to maintain normal thyroid function is classified as transient $\mathrm{CH}(\mathrm{TCH})^{7}$.

In $\mathrm{CH}$ patients with eutopic thyroid gland, it is difficult to discriminate between $\mathrm{TCH}$ and permanent $\mathrm{CH}(\mathrm{PCH})$. There have been many studies on predictors that would allow an early detection of $\mathrm{TCH}$, such as prematurity and the dose of levothyroxine during treatment ${ }^{8-10}$; however, no consensus has been achieved.

In the present study, we aimed to identify factors that could predict a transient form of $\mathrm{CH}$ 
in subjects with eutopic thyroid gland.

\section{Materials and methods}

\section{Subjects}

We retrospectively reviewed the medical records of all pediatric $\mathrm{CH}$ patients diagnosed between January 2003 and March 2015 at a single center of the University Hospital. In this period, total of 431 subjects were diagnosed with $\mathrm{CH}$ and received levothyroxine for at least 3 years. Of these 431 children with $\mathrm{CH}, 100$ subjects showed a normal-shaped thyroid gland through a thyroid scan and/or thyroid ultrasound. $\mathrm{CH}$ was diagnosed on the basis of the following thyroid function test results: low serum free thyroxine (fT4), triiodothyronine (T3), and/or abnormal TSH (TSH>10 IU/L) levels. The exclusion criteria were prematurity (gestational age $<37$ weeks), low birth weight $(<2,500 \mathrm{~g})$, birth asphyxia, congenital malformation, or chromosomal abnormalities and thyroid dysgenesis including agenesis, ectopic thyroid and small thyroid glands as identified by thyroid imaging studies. Subjects with central hypothyroidism of a hypothalamic or pituitary origin were also excluded.

\section{Study design}

All subjects with a confirmed $\mathrm{CH}$ diagnosis were immediately initiated on levothyroxine treatment and their TSH and thyroid hormone concentrations were tested every 3 months during the treatment period. The levothyroxine treatment was continued until 3 years of age and discontinued thereafter; thyroid function tests were re-evaluated 4 weeks posttherapy discontinuation. A normal thyroid function test at this time, indicating the maintenance of normal hormone concentrations without levothyroxine, confirmed the diagnosis of $\mathrm{TCH}$, and levothyroxine was not administered thereafter. Nonmaintenance of thyroid hormone concentrations without levothyroxine confirmed the diagnosis of $\mathrm{PCH}$, and the diagnosed subjects received continuous hormone replacement therapy. At 3 years of age, subjects underwent thyroid imaging studies such as thyroid ultrasound and/or thyroid scan. All enrolled subjects were performed either thyroid ultrasounds and/ or thyroid scan. Of 100 patients with $\mathrm{CH}, 83$ and 95 subjects underwent thyroid ultrasound and thyroid scan, respectively. Data regarding gestational age, birth weight, levothyroxine dose, and age at treatment initiation were collected through a review of medical records.

\section{Laboratory measurements}

Serum fT4, T3, and TSH concentrations were measured using radioimmunoassays (RIAs) (Beckman Coulter, Fullerton, CA, USA). The analytical sensitivity of the utilized RIAs were $\mathrm{ng} / \mathrm{dL}$ for fT4, $16.9 \mathrm{ng} / \mathrm{dL}$ for T3, and $0.04 \mu \mathrm{IU} / \mathrm{mL}$ for TSH.
The normal reference ranges were $0.64-1.72 \mathrm{ng} / \mathrm{dL}$ for fT4, $76.2-190.1 \mathrm{ng} / \mathrm{dL}$ for T3, and $0.15-5.00 \mu \mathrm{IU} / \mathrm{mL}$ for TSH. The within-assay coefficients of variation (CVs) were 3.1\%-10.29\% for $\mathrm{fT} 4,3.7 \%-5.3 \%$ for T3, and $3.0 \%-3.7 \%$ for TSH, and the interassay CVs were $2.5 \%-7.5 \%$ for $\mathrm{fT} 4,4.4 \%-7.6 \%$ for T3, and $2.8 \%-8.6 \%$ for TSH.

\section{Statistical analysis}

Statistical analysis was performed using IBM SPSS Statistics ver. 21.0 (IBM Co., Armonk, NY, USA). For comparison of clinical parameters between the TCH and PCH groups, Student $t$-test was performed. To identify predictive factors associated with $\mathrm{TCH}$, binary logistic regression test was performed for multivariate analysis with forward variable selection, with birth weight, gestational age, initial TSH and fT4 levels, and the levothyroxine dose as test variables. To evaluate the optimum cut-off levels of continuous biochemical predictors, we performed receiver operating characteristic (ROC) analyses with TCH as the dependent variable. Using the ROC analyses, we estimated the optimum values for all considered variables by calculating their Youden index $(\mathrm{J})$, that is the maximum vertical distance between the ROC curve and the reference or chance line $[$ maximum (sensitivity + specificity -1$)]^{11)}$. Statistical significance was defined as $P<0.05$. Results are described as mean \pm standard deviation unless otherwise stated.

\section{Results}

Of the 100 subjects ( 53 boys and 47 girls), 35 (35.0\%) were included in the PCH group and $65(65.0 \%)$ were included in the TCH group based on the defined criteria. The ratio of sex was not significantly different between TCH and PCH groups $(P=0.837)$. Subjects in the TCH group exhibited significantly lower TSH levels compared to subjects in the PCH group (Table 1). Further, the levothyroxine dose (per kg body weight) at the 1 st, $2 \mathrm{nd}$, and $3 \mathrm{rd}$ year of treatment were significantly lower in the TCH subjects (Table 1). However, subjects' age at the time of treatment initiation, initial free T4 levels, and the initial levothyroxine dose were not significantly different between the 2 groups.

In a binary logistic regression analysis with birth weight, gestational age, initial TSH and fT4 levels, and the levothyroxine dose during the treatment period as independent variables, and TCH as the dependent variable, the initial TSH levels and the levothyroxine dose at the third year of treatment were significant predictors of a TCH diagnosis (Table 2).

According to the ROC curve analyses to estimate optimal cut-offs for individual TCH predictors, an optimal levothyroxine dose (at the third year of treatment) of $2.76 \mu \mathrm{g} /$ $\mathrm{kg} /$ day was associated with a TCH diagnosis and demonstrated an $87.3 \%$ sensitivity and $67.6 \%$ specificity, with an area under the ROC curve of 0.769 (Fig. 1). The initial TSH level value of 40.2 $\mu \mathrm{IU} / \mathrm{mL}$ demonstrated a $61.9 \%$ sensitivity and $64.7 \%$ specificity, 
Table 1. Clinical and laboratory characteristics of the subjects $(n=100)$

\begin{tabular}{|c|c|c|c|c|}
\hline Characteristic & Total $(n=100)$ & Transient $\mathrm{CH}(\mathrm{n}=65)$ & Permanent $\mathrm{CH}(\mathrm{n}=35)$ & $P$-value \\
\hline Sex, male:female & $53: 47$ & $35: 30$ & $18: 17$ & $0.837^{\mathrm{a})}$ \\
\hline Birth weight (kg) & $3.2 \pm 0.3$ & $3.0 \pm 0.6$ & $3.2 \pm 0.4$ & 0.505 \\
\hline Gestational age (wk) & $39.3 \pm 1.1$ & $38.1 \pm 2.9$ & $39.2 \pm 1.7$ & 0.265 \\
\hline Age at treatment initiation (day) & $26.7 \pm 13.3$ & $27.3 \pm 14.3$ & $25.6 \pm 11.3$ & 0.550 \\
\hline Free T4 (ng/dL) & $0.74 \pm 0.41$ & $0.79 \pm 0.40$ & $0.64 \pm 0.43$ & 0.075 \\
\hline $\mathrm{T} 3$ (ng/dL) & $131.8 \pm 40.2$ & $135.5 \pm 37.7$ & $124.4 \pm 44.4$ & 0.204 \\
\hline TSH (IU/L) & $37.9 \pm 26.0$ & $30.8 \pm 18.8$ & $47.1 \pm 33.8$ & 0.005 \\
\hline \multicolumn{5}{|l|}{ Levothyroxine dose $(\mu \mathrm{g} / \mathrm{kg})$} \\
\hline Initial & $9.8 \pm 2.9$ & $9.7 \pm 2.7$ & $10.0 \pm 3.3$ & 0.637 \\
\hline $1 \mathrm{yr}$ & $3.6 \pm 1.0$ & $3.4 \pm 0.8$ & $4.1 \pm 1.3$ & 0.009 \\
\hline $2 \mathrm{yr}$ & $3.1 \pm 1.0$ & $2.7 \pm 0.5$ & $3.9 \pm 1.3$ & $<0.001$ \\
\hline $3 \mathrm{yr}$ & $2.6 \pm 0.9$ & $2.3 \pm 0.5$ & $3.3 \pm 1.2$ & $<0.001$ \\
\hline
\end{tabular}

Values are presented as mean \pm standard deviation.

$\mathrm{CH}$, congenital hypothyroidism; Free T4, free thyroxine; T3, triiodothyronine; TSH, thyroid stimulating hormone.

${ }^{a)}$ The ratio of sex was not significantly different between 2 groups using the chi-square test.

Table 2. Binary logistic regression analysis of factors associated with transient congenital hypothyroidism $\left(n=100, r^{2}=0.313\right.$, $P<0.001)$

\begin{tabular}{lccc}
\hline Variable & Estimate & Standard error & $P$-value \\
\hline TSH & 0.028 & 0.012 & 0.021 \\
$\begin{array}{l}\text { Levothyroxine dose } \\
\text { at 3rd year of treatment }\end{array}$ & 1.613 & 0.410 & $<0.001$ \\
\hline
\end{tabular}

Regression analysis contained the following independent variables entered in to the model: birth weight; gestational age; initial TSH and free thyroxine levels; and the levothyroxine dose during treatment period.

TSH, thyroid stimulating hormone.

respectively (area under the ROC curve=0.636) (Fig. 1).

\section{Discussion}

In this study, subjects with normal-shaped thyroid gland in the TCH group exhibited significantly lower initial TSH levels and received lower levothyroxine dose during the treatment period than subjects in the $\mathrm{PCH}$ group. Furthermore, the levothyroxine dose at 3 years was significantly associated with $\mathrm{TCH}$ diagnosis, and a dose of $2.76 \mu \mathrm{g} / \mathrm{kg}$ at 3 years was the optimal cutoff value that could predict TCH.

In a previous study, Messina et al. ${ }^{8)}$ reported a $\mathrm{TCH}$ prevalence of $36.5 \%$ in $64 \mathrm{CH}$ patients; however, subjects with ectopic thyroid gland were also included in the study. Ghasemi et al. ${ }^{12)}$ reported the prevalence of TCH was 3-4 times higher than permanent form with a prevalence rate of 1 in 294 live births. In a study in United States, of 33 children with primary diagnosed CH, 21 (64\%) had PCH and 12 (36\%) had $\mathrm{TCH}^{13)}$. In Korean previous studies, the proportion of $\mathrm{TCH}$ among $\mathrm{CH}$ patients ranges from $39.4 \%$ to $54.9 \%{ }^{9,14,15)}$. In our study, $65.0 \%$ of the $\mathrm{CH}$ patients with eutopic thyroid gland were diagnosed with $\mathrm{TCH}$. The higher proportion of TCH cases in our study could be due to the differences in sample size and inclusion criteria. Our study included only patients with normal shaped thyroid

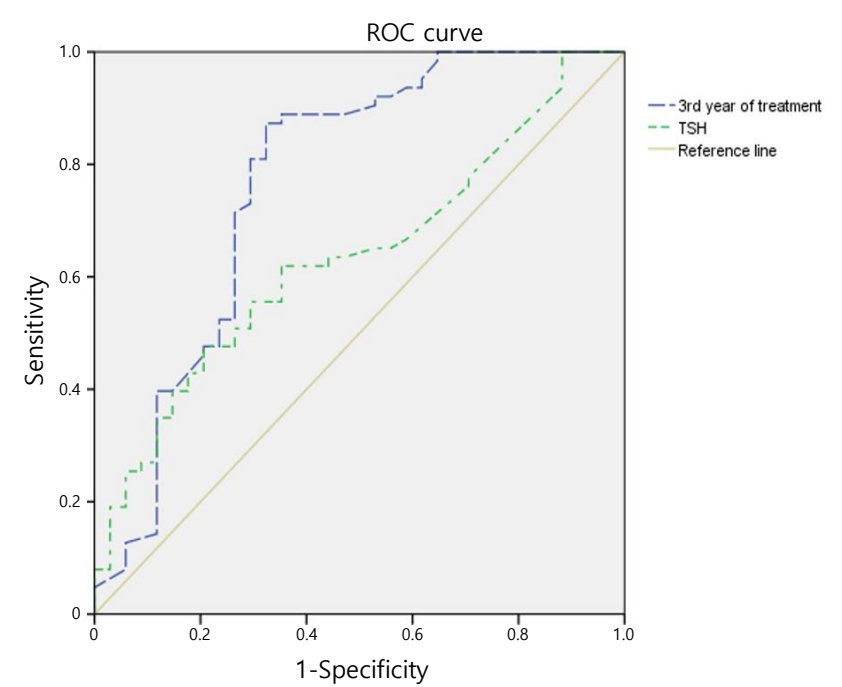

Fig. 1. Receiver operating characteristic (ROC) curves of various thresholds of thyroid stimulating hormone (TSH) (area under the curve [AUC], 0.636; 95\% confidence interval [Cl], 0.524-0.748) and the levothyroxine dose of 3rd year of treatment (AUC, $0.769 ; 95 \% \mathrm{Cl}, 0.659-0.880$ ) for predicting transient congenital hypothyroidism.

gland except thyroid dysgenesis like agenesis, hypoplasia, and ectopic thyroid gland. Therefore, our results indicate that about two-thirds of the $\mathrm{CH}$ patients with eutopic thyroid gland on the basis of neonatal screening tests may not require longer levothyroxine therapy as is the current guideline ${ }^{8)}$.

During the treatment period, the subjects in the TCH group demonstrated a lower requirement of levothyroxine than subjects in the PCH group. Moreover, the levothyroxine dose at the 3rd year of treatment was a positive predictor of TCH diagnosis. Skordis et al. ${ }^{16)}$ reported that patients with $\mathrm{TCH}$ who had a normal thyroid gland needed lower levothyroxine dose to maintain free T4 and TSH levels than patients with PCH. Unüvar et al. ${ }^{17)}$ reported that the levothyroxine dose required to maintain normal thyroid function was the only discriminatory 
marker between TCH and PCH cases. A study by Messina et al. ${ }^{8)}$ also reported a significant difference in the levothyroxine dose between the TCH and $\mathrm{PCH}$ groups. The study further reported that a levothyroxine dose of $<2.70,<2.70$, and $<2.05$ at 1,2 , and 3 years of treatment, respectively, could predict a TCH diagnosis. Cho et al. ${ }^{9)}$ reported that subjects with TCH had significantly lower levothyroxine dose requirements at 1 and 2 years of treatment than PCH-affected subjects, and the cutoff value of the levothyroxine dose at 1 and 2 years was $3.25 \mu \mathrm{g} / \mathrm{kg}$. In our study, a levothyroxine dose of $2.76 \mu \mathrm{g} / \mathrm{kg}$ at 3 years of treatment could distinguish between $\mathrm{TCH}$ and $\mathrm{PCH}$.

Initial TSH levels could also predict TCH in $\mathrm{CH}$-affected children with eutopic thyroid gland. In our study, the initial TSH levels at the time of $\mathrm{CH}$ diagnosis were significantly lower in subjects with TCH compared to those with PCH. Lim et al. ${ }^{14)}$ have similarly reported significantly lower initial TSH levels in the TCH patients. However, a few previous studies have reported that the initial fT4 and TSH levels could not differentiate between TCH and PCH cases ${ }^{8,10,15)}$.

The limitations of our study are a relatively small sample size and the retrospective study design. Also, we did not check factors that could affect thyroid function include iodine deficiency or excessive iodine intake, penetration of maternal thyroid autoantibodies, and maternal drug history such as amiodarone. Finally, the sensitivity and specificity of cutoff value in ROC analysis were relatively low to predict $\mathrm{TCH}$.

In conclusion, we demonstrated that the proportion of a transient form of $\mathrm{CH}$ were $65 \%$ of all $\mathrm{CH}$ patients with a normal shaped thyroid gland and TCH subjects had lower initial TSH levels and a lower levothyroxine dose requirement than $\mathrm{PCH}$ subjects. Therefore, TCH can be distinguished from $\mathrm{PCH}$ on the basis of the levothyroxine dose required to maintain normal thyroid function. Importantly, a levothyroxine dose lower than $2.76 \mu \mathrm{g} / \mathrm{kg}$ at 3 years may serve as a factor to predict TCH in $\mathrm{CH}$ patients with eutopic thyroid gland.

\section{Conflict of interest}

No potential conflict of interest relevant to this article was reported.

\section{References}

1. Grüters A, Krude H. Detection and treatment of congenital hypothyroidism. Nat Rev Endocrinol 2011;8:104-13.

2. LaFranchi SH. Newborn screening strategies for congenital hypothyroidism: an update. J Inherit Metab Dis 2010;33(Suppl 2):S225-33.

3. Rastogi MV, LaFranchi SH. Congenital hypothyroidism. Orphanet J Rare Dis 2010;5:17.

4. Barry Y, Bonaldi C, Goulet V, Coutant R, Léger J, Paty AC, et al. Increased incidence of congenital hypothyroidism in France from 1982 to 2012: a nationwide multicenter analysis. Ann Epidemiol 2016;26:100-5.e1-4.
5. Olivieri A, Corbetta C, Weber G, Vigone MC, Fazzini C, Medda E, et al. Congenital hypothyroidism due to defects of thyroid development and mild increase of TSH at screening: data from the Italian National Registry of infants with congenital hypothyroidism. J Clin Endocrinol Metab 2013;98:1403-8.

6. Wassner AJ, Brown RS. Congenital hypothyroidism: recent advances. Curr Opin Endocrinol Diabetes Obes 2015;22:407-12.

7. Léger J, Olivieri A, Donaldson M, Torresani T, Krude H, van Vliet G, et al. European Society for Paediatric Endocrinology consensus guidelines on screening, diagnosis, and management of congenital hypothyroidism. Horm Res Paediatr 2014;81:80-103.

8. Messina MF, Aversa T, Salzano G, Zirilli G, Sferlazzas C, De Luca F, et al. Early discrimination between transient and permanent congenital hypothyroidism in children with eutopic gland. Horm Res Paediatr 2015;84:159-64.

9. Cho MS, Cho GS, Park SH, Jung MH, Suh BK, Koh DG. Earlier re-evaluation may be possible in pediatric patients with eutopic congenital hypothyroidism requiring lower L-thyroxine doses. Ann Pediatr Endocrinol Metab 2014;19:141-5.

10. Rabbiosi S, Vigone MC, Cortinovis F, Zamproni I, Fugazzola L, Persani L, et al. Congenital hypothyroidism with eutopic thyroid gland: analysis of clinical and biochemical features at diagnosis and after re-evaluation. J Clin Endocrinol Metab 2013;98:1395-402.

11. Akobeng AK. Understanding diagnostic tests 3: receiver operating characteristic curves. Acta Paediatr 2007;96:6447.

12. Ghasemi M, Hashemipour M, Hovsepian S, Heiydari K, Sajadi A, Hadian R, et al. Prevalence of transient congenital hypothyroidism in central part of Iran. J Res Med Sci 2013;18:699-703.

13. Eugster EA, LeMay D, Zerin JM, Pescovitz OH. Definitive diagnosis in children with congenital hypothyroidism. J Pediatr 2004; 144:643-7.

14. Lim HK, Kim KH, Kim SH, No HY, Kim CJ, Woo YJ, et al. Predictors of transient hypothyroidism in neonatal screening test. J Korean Soc Pediatr Endocrinol 2006;11:506.

15. Hong SY, Chung HR, Lee SY, Shin CH, Yang SW. Factors distinguishing between transient and permanent hypothyroidism in patients diagnosed as congenital hypothyroidism by newborn screening. J Korean Soc Pediatr Endocrinol 2005; 10:154-60.

16. Skordis N, Toumba M, Savva SC, Erakleous E, Topouzi M, Vogazianos M, et al. High prevalence of congenital hypothyroidism in the Greek Cypriot population: results of the neonatal screening program 1990-2000. J Pediatr Endocrinol Metab 2005;18:453-61.

17. Unüvar T, Demir K, Abacı A, Büyükgebiz A, Böber E. The role of initial clinical and laboratory findings in infants with hyperthyrotropinemia to predict transient or permanent hypothyroidism. J Clin Res Pediatr Endocrinol 2013;5:1703. 